\title{
Design of Quasi-Elliptic Bandpass Filter for Substrate Integrated Waveguide (SIW) Using Cross Coupling Technique
}

\author{
Muhajir Mustapa, ZahrilAdha Zakaria, Noor Azwan Shairi \\ Centre for Telecommunication Research and Innovation (CeTRI), Faculty of Electronic and Computer Engineering, \\ Universiti Teknikal, Malaysia Melaka (UTeM), Hang Tuah Jaya, 76100, Durian Tunggal, Melaka, Malaysia
}

\begin{tabular}{|c|c|}
\hline Article Info & ABSTRACT \\
\hline Article history: & This paper proposes a quasi-elliptic band pass filter in substrate integrated \\
\hline Received Aug 28, 2018 & $\begin{array}{l}\text { waveguide (SIW) by using cross coupling technique to produce transmission } \\
\text { zeros (TZs) at both sides. Finally, a fourth pole SIW quasi-elliptic filter at } 5.75\end{array}$ \\
\hline Revised Oct 15, 2018 & $\mathrm{GHz}$ is designed in single layer substrate. Simulation results show that the \\
\hline Accepted Oct 28, 2018 & $\begin{array}{l}\text { filter has a center frequency of } 5.75 \mathrm{GHz} \text { with the bandwidth of } 100 \mathrm{MHz} \text {. The } \\
\text { minimum insertion loss in the passband is } 0.3 \mathrm{~dB} \text {, and the return loss is better }\end{array}$ \\
\hline Keywords: & $\begin{array}{l}\text { than } 20 \mathrm{~dB} \text {. Due to the TZs, the SIW filter has rapid transition performance at } \\
\text { both lower and upper sidebands, good selectivity is achieved, while the SIW }\end{array}$ \\
\hline Band pass filter & filter presents a very compact implementation and good spurious rejection. \\
\hline
\end{tabular}

Cross coupling

Nnegative coupling

Single layered

Substrate integrated waveguide (SIW)

\section{Corresponding Author:}

ZahrilAdha Zakaria,

Centre for Telecommunication Research and Innovation (CeTRI),

Faculty of Electronic and Computer Engineering, Universiti Teknikal,

Malaysia Melaka (UTeM), Hang Tuah Jaya, 76100, Durian Tunggal, Melaka, Malaysia.

Email: zahriladha@utem.edu.my

\section{INTRODUCTION}

Substrate integrated waveguide (SIW) have obtained an increasing number of applications in wireless communication system because integrability with planar circuit, high quality factor and low loss [1]-[12]. The single layered SIW design is easy to fabricate thus being more economic compared to other multilayered SIW design. Due to this advantage, it is frequently used in designing filters, antennas, and other devices [13]. On other hand, increasing number of applications in wireless communication with demand for narrower channels, quasi-elliptic filters with high selectivity and compactness are required. In order to create TZs at finite frequencies, both negative coupling and positive coupling are usually used in design to provide multiple path between input and output.

In this context, designing quasi-elliptic filters in SIW technology has been applied in different works like using LTCC process [1] or standard PCB process [2]-[5]. In [1] and [2], the authors proposed a negative coupling structure between SIW cavity resonators based on a balanced micro-strip line with a pair of metallized via holes. However, top and bottom layer has been used to etching slot and limiting the integrability of the device. In [3], a controllable mixed negative and positive coupling has been produced by placing short-ended strip line that is join with a conventional post wall iris. For [5], the coupling between resonator in the same layer are realized by magnetic iris window, and another coupling between resonator at the different layer are realized by coupling aperture. While in [6], the design using slot coupling at bottom layer for mainline coupling and the cross coupling using microstrip line section with open-ended stub at top layer. These structure needs a multi-layer PCB and LTCC fabrication process which increases the complexity and cost. On the other hand, a 
grounded coplanar line slot only on the top metal layer was proposed in [4] to obtain a negative coupling between standard SIW circular cavities (exciting the $\mathrm{TM}_{010}$ modes).

In this paper, we propose a single layered SIW 4-pole quasi-elliptic filter using negative coupling cross-coupling between resonators 1 and 4 is designed. A negative coupling using open-ended CPW transmission line parallel coupling with metallic via at the center SIW cavity.

\section{ANALYSIS NEGATIVE COUPLING STRUCTURE}

Figure 1 show the proposed single layered SIW negative coupling structure is embedded by etching rectangular shape slot on top surface of two adjacent rectangular SIW cavities and introducing loading capacitances as loading at center of SIW cavity. The two cavities are formed by centrally separating a bigger SIW cavity by a row of via holes. The rectangular slot is symmetrically cut between two cavities and the loading capacitances symmetrically located beside rectangular slot.

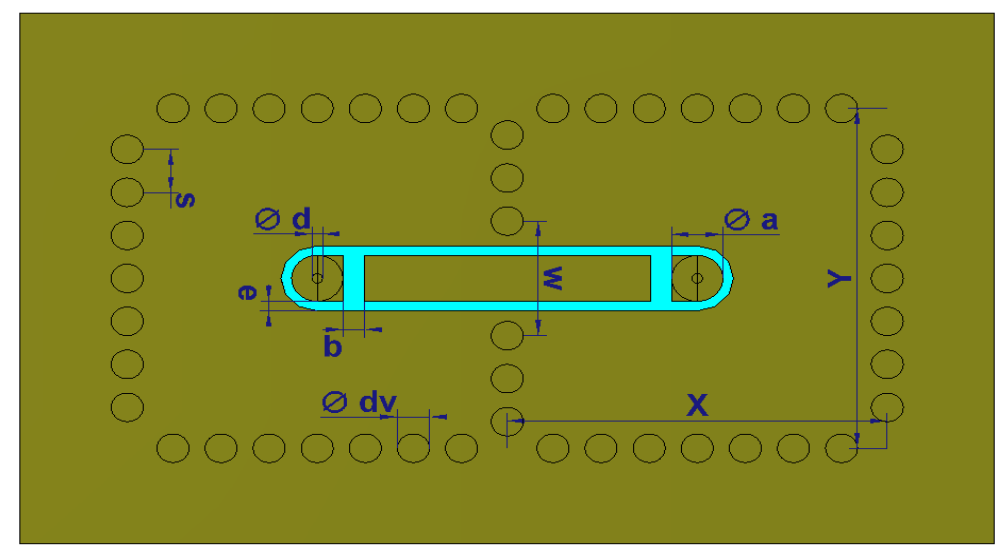

Figure 1. Topology of the electric coupling for SIW resonators

The parameters of the structure are shown in Figure 1. $a$ represent the width of the CPW transmission line along with diameter pad of via hole, while $d$ stand for the diameter of the loading capacitance. $b$ denote gap between the windows loading capacitance with CPW transmission line. $e$ is gap between top layer patch with loading capacitance and CPW transmission line. $w$ is window size between two SIW resonators while $d v$ is the diameter of via hole used to electric wall of the SIW. The $d v$ diameter is decided as $1.5 \mathrm{~mm}$ while $s$, the pitch between center to center between via hole and is decided as $2.25 \mathrm{~mm}$. The $X$ and $Y$ denote the horizontal and vertical dimension of the two identical adjacent rectangular SIW cavities.

The E-field of the first resonant mode in the proposed structure is out phase while second mode is in phase between the two SIW cavities, as shown in Figure 2. The E-field of the first resonant mode in the conventional iris coupling structure is in phase while second mode is out phase for the two adjacent cavities, as shown in Figure 3.

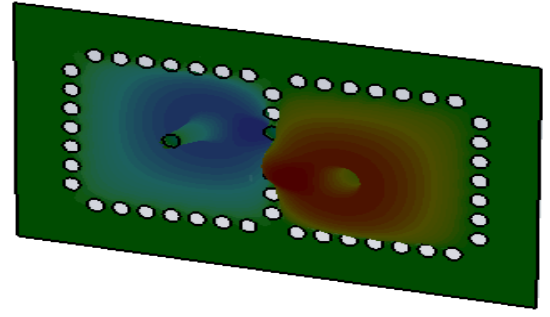

(a)

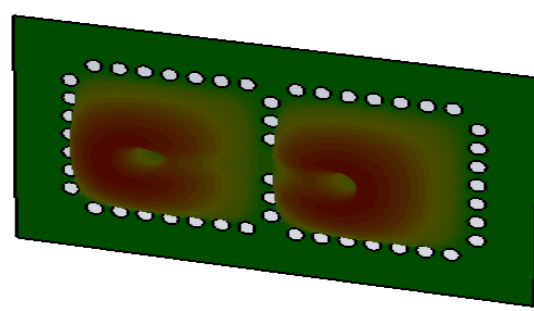

(b)

Figure 2. (a) $E$-field of the first resonant mode in the proposed structure. (b) $E$-field of the second resonant mode in the proposed structure 
The physical coupling coefficient can be calculated as given by [12].

$$
k=\frac{f_{e}^{2}-f_{m}^{2}}{f_{e}^{2}+f_{m}^{2}}
$$

Where $f_{e}$ represent the resonant frequency when E-field between two adjacent cavities is in phase, while the $f_{m}$ stand for the resonant frequency when E-field between two adjacent cavities is out phase. The condition of $k>0$ stand for positive coupling and $k<0$ represents negative coupling.

All the parameter in the proposed electric coupling structure, as shown in Figure 3, have influence on the strength of negative coupling.

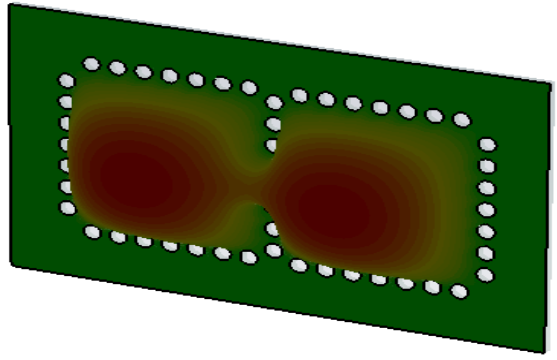

(a)

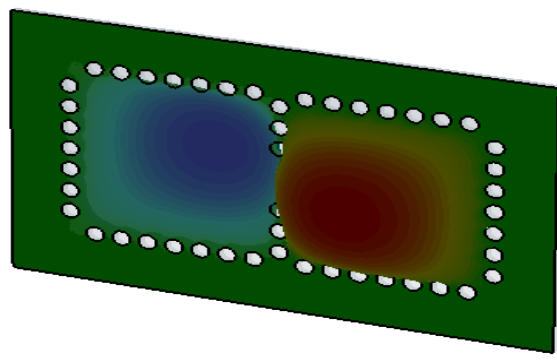

(b)

Figure 3. (a) E-field of the second resonant mode in the conventional iris coupling structure, (b) E-field of the second resonant mode in a conventional iris coupling structure

For example, the proposed negative coupling structure fabricated on the FR-4 substrate with a thickness of $h=1.6 \mathrm{~mm}$, loss tangent of 0.025 , and relative dielectric constant of $\varepsilon_{r}=4.3$ is designed and investigated by Eigen mode simulation. The simulation is completed by using CST Environment simulator. The initial values of parameter in the simulation are as follow: $a=1.6, b=1, d v=0.5, e=0.5, w=6, X=17.178$, and $Y=$ 17.178 (all in millimeters)

Figure 4 show the negative coupling coefficient of two rectangular SIW cavities with the proposed negative coupling structure $w$. It has been shown that the negative coupling coefficient increases slightly as $w$ increases from gradient 6 to $7.4 \mathrm{~mm}$.

Figure 5 illustrates the negative coupling coefficient of two rectangular SIW cavities with the proposed negative coupling structure against $a$ and $b$. It shows that the negative coupling coefficient increases slightly as $a$ increases from 1.6 to $2.4 \mathrm{~mm}$. it is also seen that the negative coupling coefficient increases rapidly as the gradient becomes small if $b$ increase from 1 to $1.8 \mathrm{~mm}$.

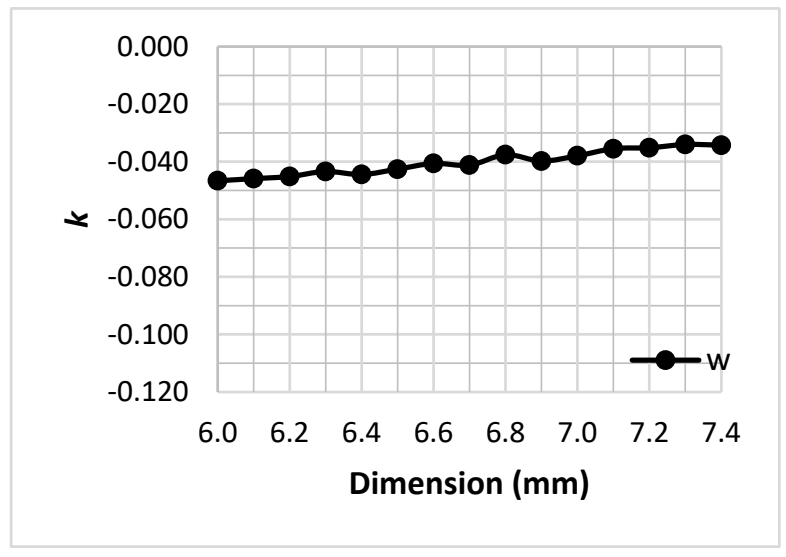

Figure 4. Negative coupling coefficient of two rectangular SIW cavities with proposed electric coupling structure against $w$ 


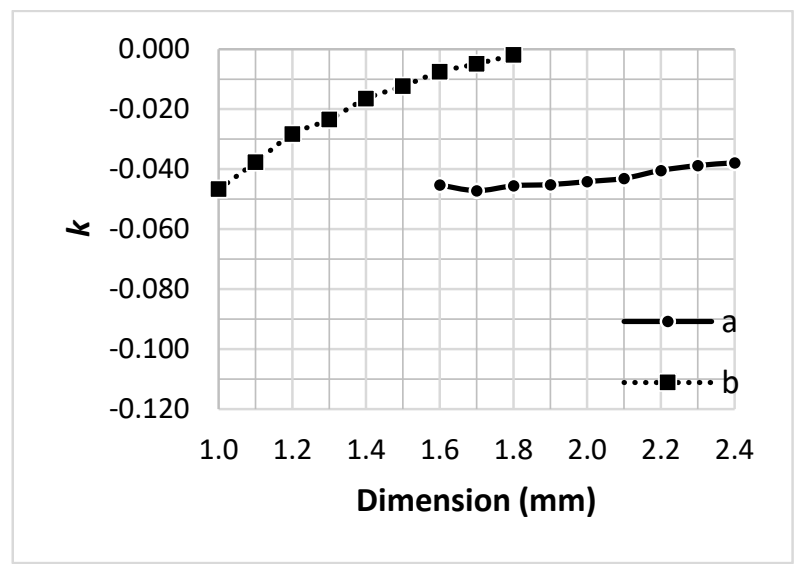

Figure 5. Negative coupling coefficient of two rectangular SIW cavities with proposed electric coupling structure against $a$ and $b$

Figure 6 illustrates the negative coupling coefficient of two rectangular SIW cavities with the proposed negative coupling structure against $d v$ and $e$. It shows that the negative coupling coefficient flat as $d v$ increases from 0.5 to $1.3 \mathrm{~mm}$. it is also seen that the negative coupling coefficient decreases rapidly as if $e$ increase from 0.5 to $1.3 \mathrm{~mm}$. Therefore, it is concluded that the parameter $b$ and $e$ significantly affect the negative coupling coefficient.

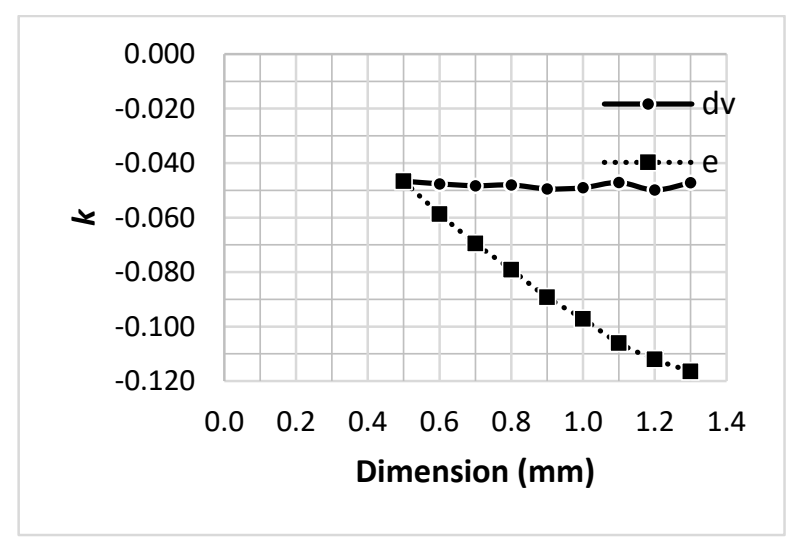

Figure 6. Negative coupling coefficient of two rectangular SIW cavities with proposed electric coupling structure against $d v$ and $e$

\section{FOUR POLE CROSS COUPLED SIW FILTER}

To apply the proposed negative coupling structure in filter, a fourth pole quasi-elliptic band pass filter working at $5.75 \mathrm{GHz}$ band with $3 \mathrm{~dB}$ bandwidth of $140 \mathrm{MHz}$ and a $1 \mathrm{~dB}$ bandwidth of $120 \mathrm{MHz}$ is designed. The topology of the filter is shown in Figure 7.

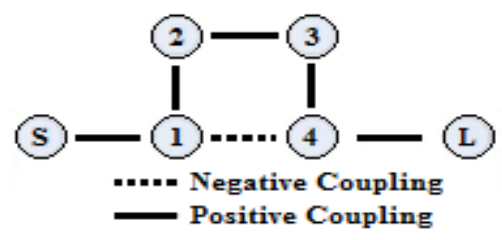

Figure 7. Topology of the fourth order quasi-elliptic band pass filter. Numbers 1-4 represent four resonators, while $S$ and $L$ denote source and load, respectively 
The $1 \mathrm{~dB}$ pass band is designed as $5.7-5.8 \mathrm{~dB}$ and two transmission zeros are designed at 5.6 and $5.9 \mathrm{GHz}$, respectively. The maximum return loss is assumed to be $20 \mathrm{db}$. The initial values of coupling coefficient and the external factor for the filter are as follows:

$$
\left\{\begin{array}{c}
k_{12}=k_{34}=0.018 \\
k_{23}=0.0138 \\
k_{14}=-0.0017 \\
Q_{e}=40.986
\end{array}\right.
$$

Where the negative sign represents the negative coupling and the positive sign the positive coupling. The positive coupling is implemented by using a magnetic iris window and its coupling coefficient is also calculated by using (1).

The configuration of the fourth pole quasi-elliptic band pass filter is based on the FR-4 substrate with a thickness of $h=1.6 \mathrm{~mm}$ and a relative dielectric constant of $\varepsilon_{r}=4.3$, as shown in Figure 8 . The dimension of the optimized filter are as follows:

\begin{tabular}{cccc}
\hline$a$ & $2 \mathrm{~mm}$ & $b$ & $2.4 \mathrm{~mm}$ \\
$d v$ & $1.5 \mathrm{~mm}$ & $e$ & $0.5 \mathrm{~mm}$ \\
$w 14$ & $5 \mathrm{~mm}$ & $X 1$ & $17.7 \mathrm{~mm}$ \\
$X 2$ & $17.7 \mathrm{~mm}$ & $Y 1$ & $17.78 \mathrm{~mm}$ \\
$Y 2$ & $19.51 \mathrm{~mm}$ & $w 01$ & $9.1 \mathrm{~mm}$ \\
$w 45$ & $9.1 \mathrm{~mm}$ & $w 12$ & $6.1781 \mathrm{~mm}$ \\
$w 34$ & $6.1781 \mathrm{~mm}$ & $w 23$ & $5.6728 \mathrm{~mm}$ \\
Lfeed & $9 \mathrm{~mm}$ & Wfeed & $3.137 \mathrm{~mm}$ \\
Lin & $8 \mathrm{~mm}$ & $d$ & $1.5 \mathrm{~mm}$ \\
s & $2.25 \mathrm{~mm}$ & & \\
\hline
\end{tabular}

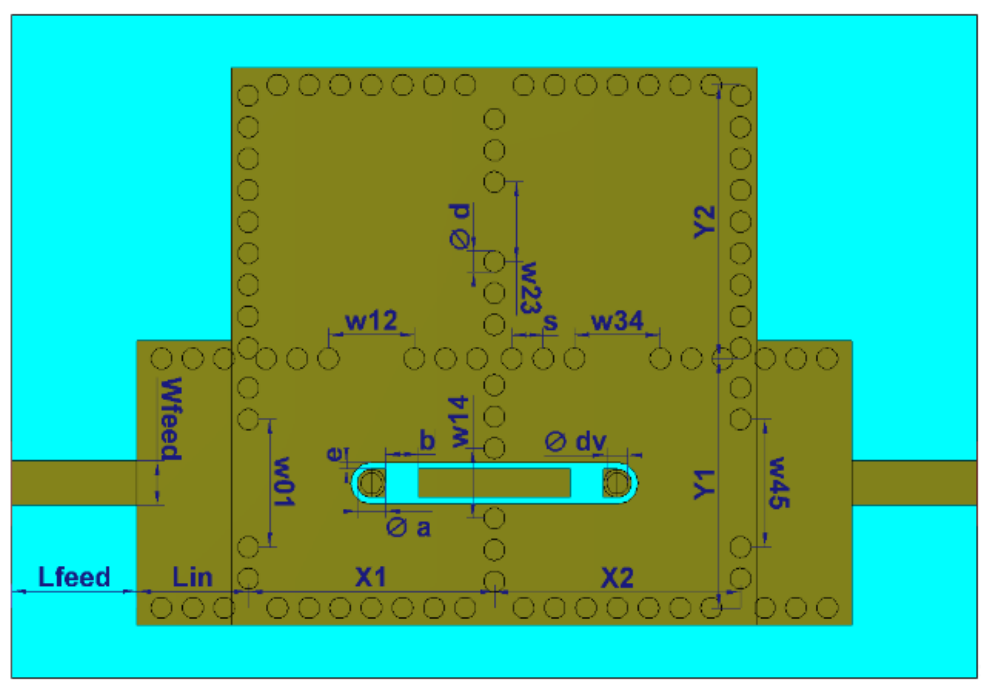

Figure 8. Configuration of the fourth pole quasi-elliptic band pass filter

\section{SIMULATION RESULTS}

The fourth pole quasi-elliptic band pass filter was designed. The simulation $S$-parameter of the filter are illustrated in Figure 9. The filter was simulated when it was enclosed in a metal box. The simulated result show that the $3 \mathrm{~dB}$ pass band range from 5.6854 to $5.8034 \mathrm{GHz}$, or a bandwidth of $2.0522 \%$. The simulated minimum insertion loss in the pass band is $0.3 \mathrm{~dB}$. The simulated transmission zero in the lower edge is located at $5.5887 \mathrm{GHz}$ and the transmission zero in the upper edge is located at $5.8924 \mathrm{GHz}$. The comparisons with exiting quasi-elliptic band pass filters employing SIW negative coupling structures are shown in Table 1. 


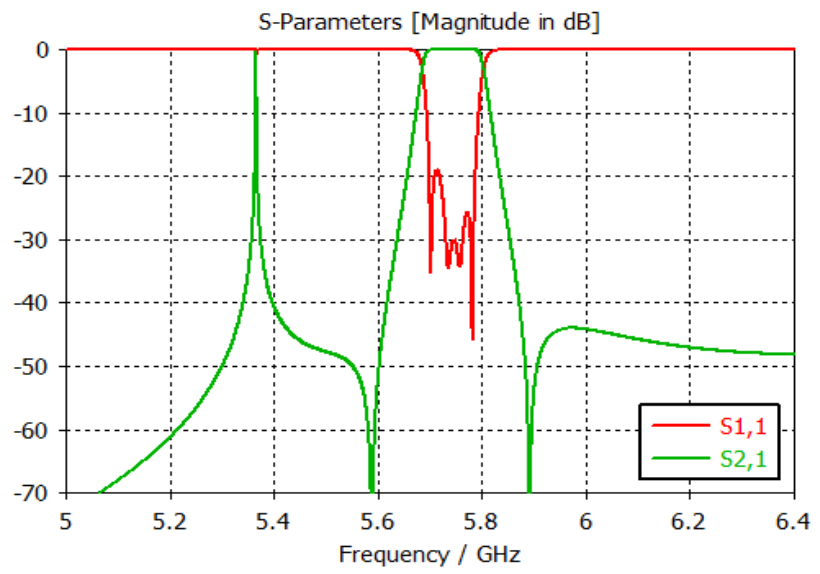

Figure 9. Simulated $S$-parameter of the fourth pole quasi-elliptic filter

Table 1. Comparison of Cross Coupled Filters in SIW Technology. (Note: B=Below, A=Above)

\begin{tabular}{ccccc}
\hline$R E F$. & $f_{0}(\mathrm{GHz})$ & $F B W$ & $\operatorname{Size}\left(\lambda_{g}^{2}\right)$ & $T Z s$ \\
\hline$[2]$ & 20.5 & $4 \%$ & $1.42 \times 1.36$ & $1 \mathrm{~B}, 1 \mathrm{~A}$ \\
{$[3]$} & 27 & $7.4 \%$ & $1.45 \times 1.14$ & $1 \mathrm{~B}, 2 \mathrm{~A}$ \\
{$[5]$} & 60 & $3.2 \%$ & $3.15 \times 2.27$ & $1 \mathrm{~B}, 1 \mathrm{~A}$ \\
{$[6]$} & 3.7 & $13.5 \%$ & - & $1 \mathrm{~B}, 1 \mathrm{~A}$ \\
{$[7]$} & 2.5 & $4 \%$ & $1.6 \times 1.6$ & $1 \mathrm{~B}, 1 \mathrm{~A}$ \\
{$[8]$} & 5.1 & $4.2 \%$ & $1.55 \times 0.98$ & $1 \mathrm{~B}, 1 \mathrm{~A}$ \\
{$[9]$} & 20 & $3 \%$ & $1.88 \times 1.42$ & $2 \mathrm{~B}, 2 \mathrm{~A}$ \\
This work & 5.75 & $2.05 \%$ & $1.45 \times 1.33$ & $1 \mathrm{~B}, 1 \mathrm{~A}$ \\
\hline
\end{tabular}

\section{CONCLUSION}

In this paper, the structure has been implemented in the single layered SIW and shown the advantages of low cost and easy fabrication. A parametric study has been carried out. This solution provides the SIW filter with a negative coupling that can be fine tuning the dimensions of an open ended CPW. Finally, it has been shown that two transmission zeros were generated at both side of pass-band, while the SIW filter presents a very compact implementation and good spurious rejection.

\section{ACKNOWLEDGMENT}

This work is supported by Universiti Teknikal Malaysia Melaka (UTeM) and the Malaysian Government (MOHE) under the research grant FRGS/1/2016/TK04/FKEKK-CeTRI/F00311.

\section{REFERENCES}

[1] G. H. Lee, C. S. Yoo, J. G. Yook and J. C. Kim, "SIW (substrate integrated waveguide) quasi-elliptic filter based on LTCC for 60-GHz application," 2009 European Microwave Integrated Circuits Conference (EuMIC), Rome, 2009, pp. 204-207.

[2] X. P. Chen and K. Wu, "Substrate Integrated Waveguide Cross-Coupled Filter With Negative Coupling Structure," in IEEE Transactions on Microwave Theory and Techniques, vol. 56, no. 1, pp. 142-149, Jan. 2008.

[3] K. Gong, W. Hong, Y. Zhang, P. Chen and C. J. You, "Substrate Integrated Waveguide Quasi-Elliptic Filters With Controllable Electric and Magnetic Mixed Coupling," in IEEE Transactions on Microwave Theory and Techniques, vol. 60, no. 10, pp. 3071-3078, Oct. 2012.

[4] B. Potelon, J. F. Favennec, C. Quendo, E. Rius, C. Person and J. C. Bohorquez, "Design of a Substrate Integrated Waveguide (SIW) Filter Using a Novel Topology of Coupling," in IEEE Microwave and Wireless Components Letters, vol. 18, no. 9, pp. 596-598, Sept. 2008.

[5] G. Zhang, J. Wang, J. Pan and H. Gu, "Compact $60 \mathrm{GHz}$ LTCC balun bandpass filter with two transmission zeroes," in Electronics Letters, vol. 51, no. 8, pp. 637-638, 1642015. doi: 10.1049/el.2014.4440

[6] R. Chen, S. Wong, Z. Guo, S. Feng and Q. Chu, "Cross-coupling on microstrip line for substrate integrated waveguide (SIW) quasi-elliptic bandpass filter," 2015 Asia-Pacific Microwave Conference (APMC), Nanjing, 2015, pp. 1-3.

[7] D. Deslandes and K.Wu, "Integrated microstrip and rectangular waveguide in planar form," IEEE Microw. Wireless Compon. Lett., vol. 11, no. 2, pp. 68-70, Feb. 2001. 
[8] K. Gong, W. Hong, Y. Zhang, P. Chen, and C. J. You, "Substrate integrated waveguide quasi-elliptic filters with controllable electric and magnetic mixed coupling," IEEE Trans. Microw. Theory Techn., vol. 60, no. 10, pp. 3071-3078, Oct. 2012.

[9] D. Deslandes and K. Wu, "Single-substrate integration technique for planar circuits and waveguide filters," IEEE Trans. Microw. Theory Techn., vol. 51, no. 2, pp. 593-596, Feb. 2003.

[10] Z. C. Hao, W. Hong, X. P. Chen, J. X. Chen, K. Wu, and T. J. Cui, "Multilayered substrate integrated waveguide (MSIW) elliptic filter," IEEE Microw. Compon. Lett., vol. 15, no. 2, pp. 95-97, Feb. 2005.

[11] L.-S. Wu, X.-L. Zhou, and W.-Y. Yin, “A novel multilayer partial H-plane implemented with folded substrate integrated waveguide (FSIW)," IEEE Microw. Compon. Lett., vol. 19, no. 8, pp. 494-496, Aug. 2009.

[12] H.-Y. Chien, T. M. Shen, T.-Y. Huang, W. H. Wang, and R. B. Wu, "Miniaturized bandpass filters with double-folded substrate integrated waveguide resonators in LTCC," IEEE Trans. Microw. Theory Techn., vol. 57, no. 7, pp. 1774-1782, Jul. 2009.

[13] L. Yan,W. Hong, G. Hua, J. Chen, K.Wu, and T. J. Cui, "Simulation and experiment on SIW slot array antennas," IEEE Microw. Wireless Compon. Lett., vol. 14, no. 9, pp. 446-448, Sep. 2004.

[14] J.-S. Hong and M. J. Lancaster, Microstrip Filter for RF/Microwave Applications. New York: Wiley, 2001, ch. 8. 